\title{
Intelligence and quality of dietary treatment in phenylketonuria
}

Department of
Child Health,
Institute of Child Health,
30 Guilford Street,
London WCIN 4NP
I Smith
M G Beasley
Department of
Paediatric Epidemiology
A E Ades
Correspondence to:
Dr Smith.
Accepted 28 December 1989
I Smith, M G Beasley, A E Ades scores, ${ }^{10}$ which seems to be occurring at about the same rate in all developed nations, ${ }^{11}$ including the United Kingdom. ${ }^{12}{ }^{13}$ In the children with phenylketonuria the associations between IQ and various aspects of diagnosis and treatment have been investigated to try and identify any that may influence outcome and providing guidelines for management.

\section{Subjects and methods}

THE PHENYLKETONURIA REGISTER

The register maintains a national list with diagnostic details of all subjects with phenylketonuria (defined as phenylalanine concentrations persistently above $480 \mu \mathrm{mol} / \mathrm{l}$ ) born from 1964 onwards. ${ }^{14}$ Two national surveys were conducted (in 1972 and 1980) to ensure that the register was complete. From the mid 1960s onwards a national programme of routine screening of urine for phenylketonuria between 3 and 6 weeks of age was progressively replaced by a system of blood testing between the 6th and 14 th days ${ }^{14}$; the change was virtually complete by 1971 . For this reason we have distinguished between children born from 1964 to 1971 (cohort 1) and those born from 1972 to 1980 (cohort 2).

The identification of subjects on the register and the protocol used for prospective follow up have been described previously. 68914 Measurement of IQ was requested within three months of the fourth birthday using the Stanford-Binet test (short form L-M, 1932 standardisation, 1960 revision). The StanfordBinet test was standardised again in $1972^{10}$ but to maintain consistency the original standardisation was adhered to throughout the study. The computation of IQs was checked by the staff of the register and corrected where necessary.

\section{CRITERA FOR INCLUSION OF SUBJECTS}

The register has on record 1031 subjects born between 1964 and 1980 who were detected by routine testing (urine or blood) and had started long term treatment with a diet low in phenylalanine before 120 days of age (table 1). Children who were treated for less than one year because they had mild phenylketonuria, and those with defects of biopterin metabolism, were excluded. In all, 808 children completed the recommended follow up protocol (table 1). Twenty three had stopped the diet before the fourth birthday, 11 because they had a mild form of phenylketonuria (blood phenylalanine concentrations $600-900 \mu \mathrm{mol} / \mathrm{l}$ on a normal diet), and 12 because treatment lapsed (blood 
Table 1 Follow up to age 4 years of children with phenylketonuria born in the United Kingdom between 1964 to 1980, who were diagnosed by routine testing and who started treatment before 4 months of age

\begin{tabular}{lll}
\hline & $\begin{array}{l}\text { No (\%) in } \\
\text { cohort l } \\
(1964-71 \text { births })\end{array}$ & $\begin{array}{l}\text { No (\%) in } \\
\text { cohort 2 } \\
(1972-80 \text { births) }\end{array}$ \\
\hline $\begin{array}{l}\text { Total omitted from the } \\
\text { study: }\end{array}$ & $156(37)$ & $67(11)$ \\
$\begin{array}{l}\text { Notified late } \\
\text { Not tested within } \\
\text { protocol }\end{array}$ & $79(19)$ & $9(1)$ \\
$\begin{array}{l}\text { Completed follow up } \\
\text { protocol }\end{array}$ & $77(18)$ & $58(10)$ \\
\hline Total & $263(63)$ & $545(89)$ \\
\hline
\end{tabular}

phenylalanine concentrations over $1200 \mu \mathrm{mol} / \mathrm{l}$ ); these 23 patients were included in the study. No attempt was made to differentiate between subjects with severe or less severe phenylketonuria.

Of the 223 children who were treated early but omitted from the study (table 1) some had been notified late so did not enter follow up, and others were not assessed according to the study protocol. Sixteen children (eight in each cohort) died before they were 4 years old. Some form of psychological assessment had been carried out between 2 and 6 years of age in 193 subjects using various test procedures. After adjustment for the different methods used to assess IQ, twice as many had IQs of less than 70 compared with the study group. This bias in selection has led to a small overestimate of the average IQ in children with phenylketonuria treated early, but does not affect the interpretation of comparative analyses of diagnostic and treatment factors.

\section{STANDARDISATION OF IQ SCORES}

In the absence of a control group it was necessary to use some other method of allowing for the large changes in population IQ scores that has occurred during the period of the study and which might be incorrectly interpreted as 'improvement'. ${ }^{12}$ In a detailed analysis of American IQ data Flynn showed that mean IQ scores with all the commonly used tests have risen at a rate of roughly 0.3 points/year from standardisation onwards. ${ }^{10}$ No comparable analysis exists for the United Kingdom but two published studies suggest that similar rises in IQ scores have occurred. ${ }^{12}{ }^{13}$ Other studies that have used IQ to assess intellectual development support this view.

A study of a representative population of 11 year old children on the Isle of Wight was carried out in 1964/5 using the short form of the Wechsler intelligence scale for children (WISC). ${ }^{15}$ The mean IQ was reported as 107 , a figure close to the predicted figure based on Flynn's analysis of 106 . In a continuing national study of children with congenital hypothyroidism patients and matched controls are being tested at 5 years of age using the Wechsler preschool and primary scale of intelligence (WPPSI). ${ }^{16}$ The mean IQ in the controls group of over 150 subjects is currently 111 (P Fuggle, I Smith, unpublished observations), compared with a predicted figure of 109 .
Having established that trends in IQ scores in the United Kingdom were comparable with those in the United States it was decided to use Flynn's analysis to calculate revised IQ norms. The Stanford-Binet test was originally standardised in 1932 to give a mean (SD) of 100 (16). Flynn's analysis ${ }^{10}$ of Stanford Binet IQ trends in white children (no black, and only a few Asian children were recorded on the register) includes a revised standardisation mean of 98 . Revised IQ norms were calculated for each year of testing as follows: revised norm $=98+0.3$ (test year - 1932). IQs in children on the register were converted to SD scores (IQ SD scores) based on these norms: IQ SD score $=$ (actual IQ - revised IQ norm for test year)/16.

\section{ASSESSMENT OF QUALITY OF TREATMENT}

The method of diagnosis (urine or blood testing), whether or not the phenylalanine concentrations at diagnosis were above $1200 \mu \mathrm{mol} / \mathrm{l}$, and the age in days at the start of treatment were recorded for every patient: quantitative measurements of diagnostic plasma phenylalanine concentrations were available in $85 \%$ of subjects. Serial blood phenylalanine concentrations during treatment were categorised and plotted as described previously, ${ }^{6} 17$ and the average phenylalanine concentrations (area under the curve divided by time) were calculated for the period from the start of treatment to the fourth birthday. Periods of unusually low phenylalanine concentrations were assessed by calculating the total length of time during which the plot of phenylalanine concentrations remained below $120 \mu \mathrm{mol} / 1$ during the first 2 years of life; after 2 years of age few measurements were below 120 $\mu \mathrm{mol} / \mathrm{l}$.

\section{SOCIAL CLASS}

Social class was defined for the family breadwinner at the time of the child's birth according to the Registrar General's classification of occupations at the 1971 census, ${ }^{18}$ and was compared with the national data. ${ }^{19}$

\section{ANALYSIS OF DATA}

The association between IQ SD score at the age of 4 years and demographic, diagnostic, and treatment variables was explored in a series of tables. As many of the variables were correlated, multiple regression was used to assess their independent effects upon IQ SD score. There were missing values for some variables, notably quantitative phenylalanine measurements at diagnosis, so that the tables do not all refer to exactly the same number of subjects.

\section{Results}

TEMPORAL CHANGES IN SCREENING AND IN IQ Table 2 summarises the diagnostic details and IQ scores for all 808 subjects in the study. Data are given for each annual birth cohort and the combined data for cohorts 1 and 2. The calculated population IQ norms and mean IQ SD scores are shown with the mean IQ values. 
Table 2 Diagnostic details and intelligence at 4 years of age in subjects with phenylketonuria grouped according to year of birth

\begin{tabular}{|c|c|c|c|c|c|c|c|}
\hline $\begin{array}{l}\text { Year of } \\
\text { birth }\end{array}$ & $\begin{array}{l}\text { No of } \\
\text { subjects }\end{array}$ & $\begin{array}{l}\% \text { Detected } \\
\text { by urine } \\
\text { testing }\end{array}$ & $\begin{array}{l}\% \text { With diagnostic } \\
\text { phenylalanine } \\
\text { concentration } \\
>1200 \mu \mathrm{mol} / \mathrm{l}\end{array}$ & $\begin{array}{l}\% \text { Treated } \\
\text { before } 21 \\
\text { days old }\end{array}$ & Mean IQ & $\begin{array}{l}\text { Mean IQ: } \\
\text { estimated } \\
\text { population } \\
\text { norms }\end{array}$ & $I Q S D$ scores \\
\hline $\begin{array}{l}\text { Cohort } 1: \\
1964 \\
1965 \\
1966 \\
1967 \\
1968 \\
1969 \\
1970 \\
1971 \\
\text { Total } 1964-71\end{array}$ & $\begin{array}{r}14 \\
16 \\
13 \\
30 \\
30 \\
44 \\
59 \\
58 \\
263\end{array}$ & $\begin{array}{r}71 \\
94 \\
69 \\
60 \\
67 \\
27 \\
3 \\
2 \\
33\end{array}$ & $\begin{array}{r}86 \\
100 \\
77 \\
83 \\
90 \\
86 \\
85 \\
90 \\
87\end{array}$ & $\begin{array}{l}36 \\
19 \\
31 \\
40 \\
23 \\
48 \\
59 \\
71 \\
48\end{array}$ & $\begin{array}{r}85 \\
82 \\
89 \\
94 \\
97 \\
94 \\
99 \\
101 \\
96\end{array}$ & $\begin{array}{l}108 \cdot 8 \\
109 \cdot 1 \\
109 \cdot 4 \\
109 \cdot 7 \\
110 \cdot 0 \\
110 \cdot 3 \\
110 \cdot 6 \\
110 \cdot 9 \\
109 \cdot 8\end{array}$ & $\begin{array}{l}-1.50 \\
-1.72 \\
-1.29 \\
-0.96 \\
-0.82 \\
-1.02 \\
-0.72 \\
-0.63 \\
-0.92\end{array}$ \\
\hline $\begin{array}{l}\text { Cohort } 2: \\
1972 \\
1973 \\
1974 \\
1975 \\
1976 \\
1977 \\
1978 \\
1979 \\
1980 \quad 1972-80\end{array}$ & $\begin{array}{r}59 \\
65 \\
59 \\
59 \\
56 \\
59 \\
64 \\
63 \\
61 \\
545\end{array}$ & $\begin{array}{r}10 \\
0 \\
3 \\
0 \\
0 \\
0 \\
0 \\
0 \\
0 \\
1\end{array}$ & $\begin{array}{l}81 \\
86 \\
90 \\
86 \\
84 \\
78 \\
75 \\
83 \\
71 \\
81\end{array}$ & $\begin{array}{l}61 \\
77 \\
71 \\
80 \\
70 \\
69 \\
77 \\
73 \\
80 \\
73\end{array}$ & $\begin{array}{l}99 \\
104 \\
106 \\
107 \\
102 \\
104 \\
103 \\
106 \\
105 \\
104\end{array}$ & $\begin{array}{l}111 \cdot 2 \\
111 \cdot 5 \\
111 \cdot 8 \\
112 \cdot 1 \\
112 \cdot 4 \\
112 \cdot 7 \\
113.0 \\
113 \cdot 3 \\
113.6 \\
112 \cdot 4\end{array}$ & $\begin{array}{l}-0.79 \\
-0.47 \\
-0.36 \\
-0.31 \\
-0.62 \\
-0.53 \\
-0.64 \\
-0.48 \\
-0.59 \\
-0.53\end{array}$ \\
\hline
\end{tabular}

The change from urine to blood screening was made in 1969/70 and, as expected, was accompanied by an increase in the proportion of children treated before 21 days of age. Throughout the study most of the patients had diagnostic blood phenylalanine concentrations above $1200 \mu \mathrm{mol} / \mathrm{l}$, although the proportion seemed to decline somewhat in the late $70 \mathrm{~s}$. Mean IQs rose from around 85 in the mid 60 s to well above 100 by the mid 70s. The rise began in 1966/7 before the changes in the screening programme, but ended as the changes were completed. The rise in IQ was consistent across all health regions and all large clinics (not shown); it even occurred in Scotland where vir- tually all patients were detected by blood testing from 1965 onwards.

Between 1964 and 1971 births (cohort 1) the average rate of rise in IQ was approximately 2 points/year, seven times the rate estimated to have occurred in the general population. Mean IQs never reached the revised IQ norms, however (table 2); children born after 1972 (cohort 2) still having mean IQ eight points below the norms. The percentage of children with IQs more than 2 SD below the norms were $19 \%$ in cohort 1 and $8 \%$ in cohort 2 . Despite the changes in mean IQ, SD scores (not shown) were stable around the expected value of 16 (pooled value 16:36). IQ SD scores rose from

Table 3 IQ SD score by method of testing, diagnostic phenylalanine concentration, age at start of treatment, average phenylalanine concentration during treatment, and length of time that phenylalanine concentration was below 120 umol// during the first two years

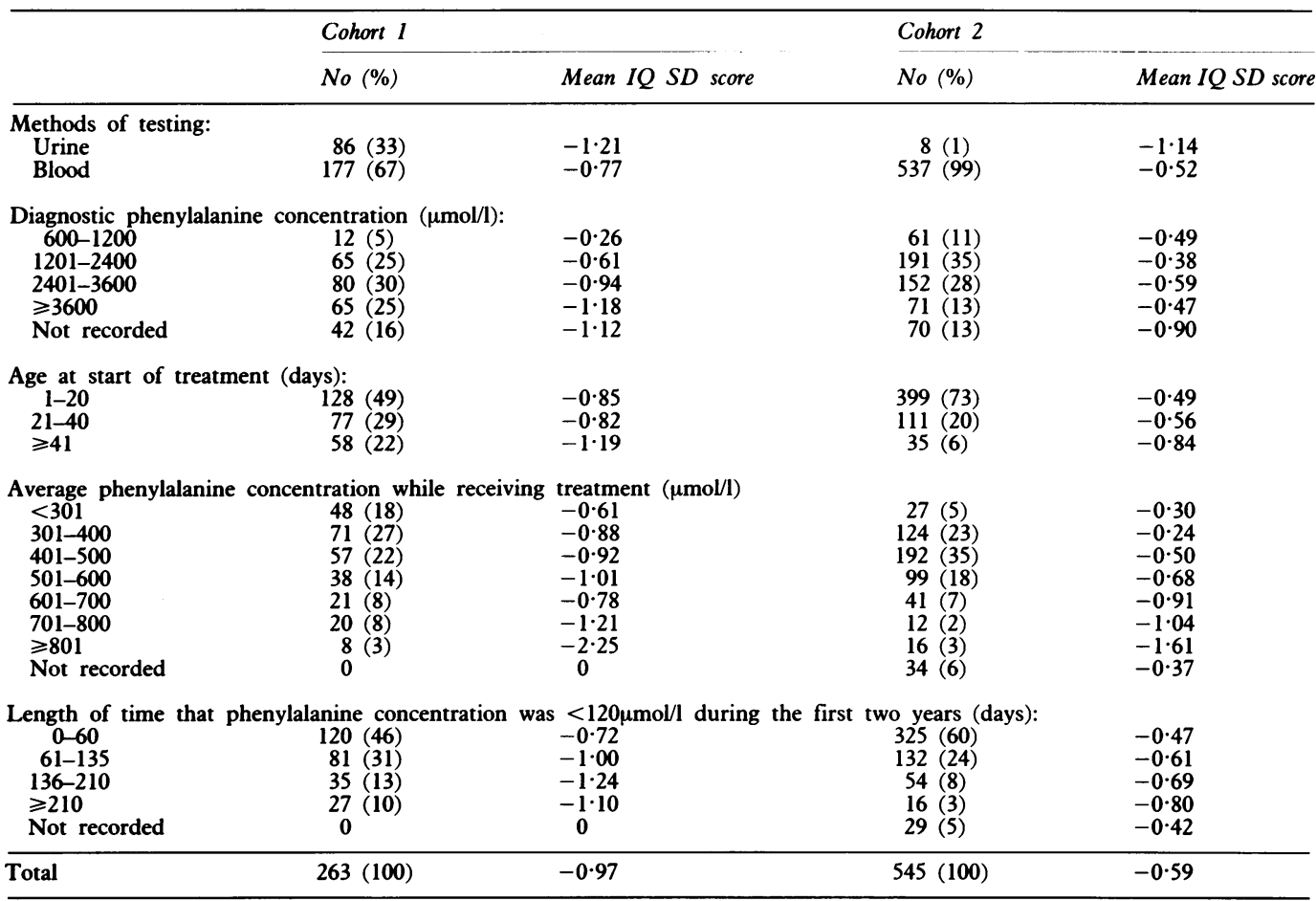


-1.5 to -0.6 in cohort 1 and, in cohort 2 , remained around -0.5 .

ASSOCIATION BETWEEN IQ AND TREATMENT All the analyses were carried out using IQs expressed as SD scores; the lower the IQ the more negative the IQ SD score. Table 3 shows the association between IQ SD scores and the main diagnostic and treatment variables. Subjects in cohort 1 did consistently worse than subjects in cohort 2 , and subjects detected by urine screening did worse than those detected by blood screening. Cohort 1 tended to have higher concentrations of phenylalanine at diagnosis than cohort 2, and IQ SD scores became more negative as diagnostic phenylalanine concentrations rose only in cohort 1 . Treatment was started earlier in children detected by blood screening, and treatment before 21 days of age was therefore much less common in cohort 1 . In both cohorts earlier treatment was associated with less negative IQ SD scores.

The average phenylalanine concentrations during treatment in the first 4 years of life were similar in the two cohorts (overall mean: cohort $1,455 \mu \mathrm{mol} / 1$; cohort $2,473 \mu \mathrm{mol} / \mathrm{l}$ ). In both cohorts subjects with higher average phenylalanine concentrations had more negative IQ SD scores. There was no indication that the worse outcome in cohort 1 compared with cohort 2 was due to higher phenylalanine concentrations, although longer periods of low phenylalanine concentrations $(<120 \mu \mathrm{mol} / \mathrm{l})$ were commoner in cohort 1 , and in both cohorts were associated with worse outcome. Though year of birth, age of starting treatment, and phenylalanine concentrations at diagnosis were interrelated, none of these factors were associated with average phenylalanine concentrations during treatment.

\section{EFFECTS OF SOCIAL CLASS}

The proportions of subjects in each social class were similar to those in the general population. ${ }^{19}$ In both cohorts IQ SD score was strongly associated with social class, and there was also a modest association between social class and average phenylalanine control during treatment, subjects in social classes I and II having somewhat lower average phenylalanine concentrations than those in classes IV and V (table 4). In social classes I, II, and III there was a tendency for subjects in cohort 2 to have rather higher average phenylalanine concentrations than subjects in cohort 1 . There was no association between social class and year of birth, method of screening, age at the start of treatment, phenylalanine concentrations at diagnosis, or duration of low phenylalanine concentrations.

\section{MULTIPLE REGRESSION ANALYSES}

The independent effects of five variables on IQ SD scores (age at start of treatment, diagnostic phenylalanine concentrations, average phenylalanine concentrations during treatment, duration of phenylalanine concentrations below 120 $\mu \mathrm{mol} / \mathrm{l}$ in the first 2 years of life, and social class)

Table 4 IQ SD score, phenylalanine control, and social class

\begin{tabular}{|c|c|c|c|c|c|c|}
\hline \multirow[t]{2}{*}{ Social class } & \multicolumn{3}{|l|}{ Cohort 1} & \multicolumn{3}{|l|}{ Cohort 2} \\
\hline & No (\%) & $\begin{array}{l}\text { Mean IQ } \\
S D \text { score }\end{array}$ & $\begin{array}{l}\text { Mean } \\
\text { phenylalanine } \\
\text { concentration } \\
(\mu \mathrm{mol} / \mathrm{l})\end{array}$ & No (\%) & $\begin{array}{l}\text { Mean IQ } \\
S D \text { score }\end{array}$ & $\begin{array}{l}\text { Mean } \\
\text { phenylalanine } \\
\text { concentration } \\
(\mu \mathrm{mol} / \mathrm{l})\end{array}$ \\
\hline $\begin{array}{l}\text { I } \\
\text { II } \\
\text { IIInm } \\
\text { IIIm } \\
\text { IV } \\
\text { V } \\
\text { Armed forces } \\
\text { Unemployed or missing }\end{array}$ & $\begin{aligned} & 11(4) \\
& 36(14) \\
& 18(7) \\
& 95(36) \\
& 49(19) \\
& 32(12) \\
& 7(3) \\
& 15(5)\end{aligned}$ & $\begin{array}{l}-0.15 \\
-0.14 \\
-0.48 \\
-0.89 \\
-1.32 \\
-1.50 \\
-0.83 \\
-1.53\end{array}$ & $\begin{array}{l}393 \\
435 \\
410 \\
432 \\
478 \\
520 \\
470 \\
478\end{array}$ & $\begin{aligned} & 41(7) \\
& 86(16) \\
& 28(5) \\
& 213(39) \\
& 70(13) \\
& 36(7) \\
& 19(3) \\
& 32(9)\end{aligned}$ & $\begin{array}{l}-0.09 \\
-0.14 \\
-0.17 \\
-0.53 \\
-0.76 \\
-1.27 \\
-0.63 \\
-0.84\end{array}$ & $\begin{array}{l}424 \\
443 \\
483 \\
470 \\
486 \\
512 \\
461 \\
535\end{array}$ \\
\hline
\end{tabular}

Table 5 Multiple regression: IQ SD score and factors associated with diagnosis and treatment

\begin{tabular}{|c|c|c|c|c|c|}
\hline \multirow[t]{2}{*}{ Covariates } & \multirow[b]{2}{*}{$d f$} & \multicolumn{2}{|c|}{$\begin{array}{l}\text { Cohort } 1 \quad(n=220) \\
\text { Intercept } 1 \cdot 26(0.6 \text { to } 1 \cdot 9)\end{array}$} & \multicolumn{2}{|c|}{$\begin{array}{l}\text { Cohort } 2(n=437) \\
\text { Intercept } 0.52(0.0 \text { to } 1 \cdot 1)\end{array}$} \\
\hline & & $F$ & Estimates $(95 \% C I)$ & $F$ & Estimates $(95 \% C I)$ \\
\hline $\begin{array}{l}\text { Diagnostic phenylalanine concentration }(\mu \mathrm{mol} / \mathrm{l}) \text { : } \\
\quad 1-1200 \dagger \\
1201-2400 \\
2401-3600 \\
\geqslant 3601\end{array}$ & 3 & $5 \cdot 14^{* *}$ & $\begin{array}{l}0 \\
-0.40(-1.0 \text { to }+0.2) \\
-0.68(-1.2 \text { to }-0.1) \\
-0.89(-1.4 \text { to }-0.3)\end{array}$ & $0 \cdot 80 \ddagger$ & $\begin{array}{l}0 \\
+0.07(-0.2 \text { to }+0.4) \\
-0.05(-0.4 \text { to }+0.3) \\
+0.15(-0.2 \text { to }+0.5)\end{array}$ \\
\hline Age in months at start of treatment & 1 & $8 \cdot 81^{* *}$ & $-0.25(-0.4$ to -0.1$)$ & $4 \cdot 65^{*}$ & $-0.24(-0.5$ to -0.0$)$ \\
\hline $\begin{array}{l}\text { Mean phenylalanine concentration }(\mu \mathrm{mol} / \mathrm{l}) \text { : } \\
0-300 \dagger \\
301-400 \\
401-500 \\
501-600 \\
601-700 \\
701-800 \\
801-1350\end{array}$ & 6 & $3 \cdot 43^{* *}$ & $\begin{array}{l}0 \\
-0.41(-0.8 \text { to }-0.0) \\
-0.70(-1.1 \text { to }-0.3) \\
-0.35(-0.8 \text { to }+0.1) \\
-0.37(-0.9 \text { to }+0.2) \\
-0.76(-1.3 \text { to }-0.2) \\
-1.37(-2.2 \text { to }-0.6)\end{array}$ & $5 \cdot 78^{* * *}$ & $\begin{array}{l}0 \\
-0.04(-0.5 \text { to }+0.4) \\
-0.23(-0.2 \text { to }+0.2) \\
-0.41(-0.9 \text { to }+0.1) \\
-0.62(-1.2 \text { to }-0.1) \\
-0.86(-1.6 \text { to }-0.2) \\
-1.41(-2.1 \text { to }-0.7)\end{array}$ \\
\hline $\begin{array}{l}\text { Months that blood phenylalanine concentration } \\
<120 \mu \mathrm{mol} / \mathrm{l} \text { : }\end{array}$ & 1 & $4 \cdot 26^{*}$ & $-0.05(-0.1$ to -0.0$)$ & $10 \cdot 14^{* *}$ & $-0.08(-0.1$ to -0.0$)$ \\
\hline $\begin{array}{l}\text { Social Class } \\
\text { I, II, IIInm } \\
\text { IIIm and armed forces } \\
\text { IV, V, and unemployed, and missing }\end{array}$ & 2 & $24 \cdot 1^{* * *}$ & $\begin{array}{l}0 \\
-0.66(-1.0 \text { to }-0.3) \\
-1.15(-1.5 \text { to }-0.8)\end{array}$ & $19 \cdot 22^{* * *}$ & $\begin{array}{l}0 \\
-0.46(-0.7 \text { to }-0.2) \\
-0.77(-1.0 \text { to }-0.5)\end{array}$ \\
\hline
\end{tabular}




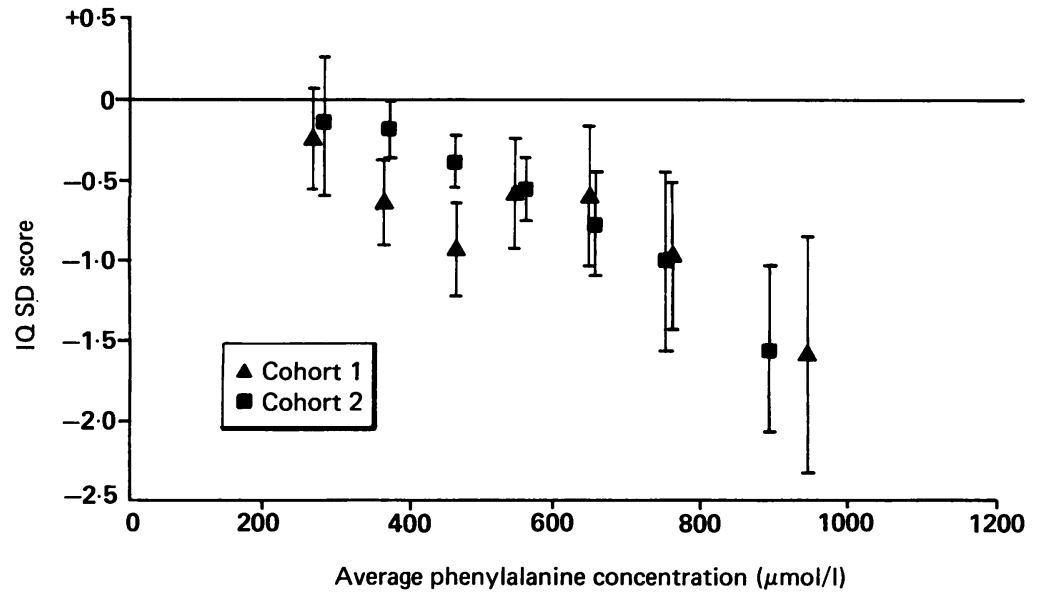

Mean IQSD scores and $95 \%$ confidence intervals compared with average phenylalanine control between the start of treatment and the fourth birthday, adjusted for other variables by regression. 'worst' dietary control (average phenylalanine concentrations $>800 \mu \mathrm{mol} / \mathrm{l}$ ) had mean IQs over $1 \mathrm{SD}$ below those in subjects with the 'best' control (average phenylalanine concentrations $<301 \mu \mathrm{mol} / \mathrm{l})$.

Less than $10 \%$ of subjects in either cohort had all the most favourable diagnostic and treatment characteristics (diet before 21 days of age, average phenylalanine concentrations below 400 $\mu \mathrm{mol} / \mathrm{l}$, and periods of low phenylalanine concentrations lasting less than two months). In those who did (16 in cohort 1 , and 46 in cohort $2)$, after standardising for social class, mean IQ was 100 in cohort 1 and 112.6 in cohort 2 . The mean IQs in the same groups of children predicted by the regression equations were 104 and $112 \cdot 6$, respectively, compared with IQ norms of $109 \cdot 8$ and $112 \cdot 4$. Thus in cohort 1 , even children who received the 'best treatment' had IQs well below the population norms and did much worse than similar children in cohort 2 , who seemed to achieve optimal scores.

were examined by multiple regression (table 5). Preliminary analyses had shown that method of diagnosis was not significant in either cohort once these five covariates had been taken into account (adjusted mean differences in IQ SD scores between subjects urine diagnosed by blood tests were 0.13 in cohort $1,(p=0.42)$ and 0.04 in cohort $2, p=0.93$ ). Birth year (which had no effect in cohort 2) was still significant in cohort 1 when the other variables were accounted for. After adjustment for the other variables the estimated annual rise in IQ SD scores fell from $0.126(1.9 \mathrm{IQ}$ points $) /$ year $(p=0.0005)$ to $0.084(1.3 \mathrm{IQ}$ points $)(\mathrm{p}=0.014) /$ year, and addition of birth year to the analysis somewhat reduced the effects of age at the start of treatment and of low phenylalanine concentrations (making the latter not a significant variable). Birth year, however, had negligible effects on the other measurements and, as it was not significant in cohort 2 , it was decided to omit it from the regression analyses.

In cohort 1 a more negative IQ SD score was independently and significantly associated with each of the variables included in the analysis (table 5) and the relationships were not significantly different from linear. In cohort 2 , despite the higher mean $I Q$, the results were strikingly similar except that IQ SD scores showed no association with higher phenylalanine concentrations at diagnosis. There were no significant interactions between the variables in either cohort. When the analysis was repeated with the two cohorts combined (adding a variable to distinguish them) the results were similar, although being in cohort 1 was still associated with a worse outcome (actual difference in IQ SD score 0.407 , adjusted difference 0.263 , $\mathrm{p}=0.0026$ ); there was, as could be expected, significant interaction between diagnostic phenylalanine concentrations and birth cohort $(p=0.01)$ but not between birth cohort and any other variables.

The influence of average phenylalanine control on IQ SD scores in cohorts 1 and 2, adjusted using least square means for the effects of four other covariates, is illustrated in the figure. The trends were similar and not significantly different from linear. Subjects with the

\section{Discussion}

Interpretation of the IQ results in the present study depends to some extent on the assumptions made concerning the trends in IQ scores in the general population. There is good evidence that in the United Kingdom children's IQ scores have been rising steadily ( $P$ Fuggle, I Smith, unpublished observations), just as in the United States. ${ }^{12} 1315$ Although the method we have used to allow for population IQ trends is only an approximation, it has the merit of emphasising low a rise in population IQ scores above 100 may lead to over optimistic interpretation of IQ data in children at risk. It also explains why children with phenylketonuria who are treated early, despite having apparently 'normal' IQs, also have cognitive deficits, ${ }^{20} 21$ incidence of behavioural problems, notably hyperactivity. 67

In children treated early and born in the mid $60 \mathrm{~s}$, mean IQ was over I SD (16 points) below the revised norms, and even in children born in the late 70 s the mean IQ was still $0.5 \mathrm{SD}(8$ points) below the norms. It should be emphasised that the reduction was the result of a general shift downwards in scores, rather than to the presence of a minority of children with particularly low IQs. A total of $19 \%$ of children born between 1964 and 1971, and 8\% of those born in the mid 70s, had IQs more than 2 SD below the norms. Such children are likely to experience serious educational and employment problems. Had the usual figure of 70 been taken as the bottom limit of normal, only $7 \%$ and $2 \%$, respectively, would have been considered to be in this group. As children excluded from our study seem to have done rather worse we may have underestimated the size of the problem.

The study did not fully explain why, nationwide, children born in the $60 \mathrm{~s}$ did so much worse than children born in the $70 \mathrm{~s}$, although a later start to treatment and more prolonged hypophenylalaninaemia seemed to contribute. We have considered the possibility that the rise in IQ was a result of an increase in the proporeducational difficulties, ${ }^{45}$ and an increased 
tion of children with less severe phenylketonuria, but we have previously failed to find an independent effect of the type of phenylketonuria on outcome once allowance was made for phenylalanine control. ${ }^{17}$ Nor are we aware of any important changes in treatment policies or product composition (including tyrosine content) coinciding with the rise in IQ. ${ }^{22}{ }^{23}$ On the other hand, nutritional expertise increased rapidly during the 60 s and may have benefited children born later.

The IQ data presented here are in accord with those of other countries, ${ }^{25} 24$ although our conclusions about the implications for long term intellectual development are rather less optimistic. The American Collaborative Study, which reported a mean IQ at 4 years on the Stanford Binet (1960 revision) of 103 , concluded that the children were making good progress, although this mean was five to seven points below that in unaffected siblings and parents, ${ }^{2}{ }^{34}$ a reduction similar to that found in the present study. The associations between intellectual progress and the different measures of the quality of treatment were also consistent with data reported by others. ${ }^{24-27}$ Nevertheless it was surprising that hypophenylalaninaemia seemed to influence outcome even in children born in the mid 70s when overt phenylalanine deficiency was rarely seen.

In the present study IQ fell linearly by roughly $0.25 \mathrm{SD}$ (four IQ points) for each month between birth and starting treatment, for each $300 \mu \mathrm{mol} / 1$ rise in average phenylalanine concentrations, and for each five months during the first two years during which phenylalanine concentrations were below $120 \mu \mathrm{mol} / \mathrm{l}$. Fewer than $10 \%$ of subjects achieved the 'best treatment' according to the criteria derived from our study. Although it is not possible to be certain that the association between quality of treatment and IQ is one of cause and effect, this seems the likeliest explanation.

Nevertheless, alternatives have to be considered. For example, even after allowing for the large effect of social class on IQ, less able children might have parents who are less successful at controlling the diet, or less able children might be harder to treat. Another possibility is that phenylalanine control is dependent on the severity of the defect, and that severity affects outcome for reasons other than phenylalanine control.

A previous controlled trial of strict $(60-360$ $\mu \mathrm{mol} / \mathrm{l}$ ) compared with less strict phenylalanine control (361-720 $\mu \mathrm{mol} / \mathrm{l})$ failed to show any significant benefit from stricter treatment, ${ }^{28}$ and resulted in a long held view that it was 'safe' to let phenylalanine concentrations rise to 600 $700 \mu \mathrm{mol} / \mathrm{l}$. The groups in the trial showed a large overlap in phenylalanine concentrations, however, and those who received the stricter diet did have a mean IQ at 3 years of age that was four points above the mean in those who had received the more relaxed diet. In addition, some clinics that achieve strict control of blood phenylalanine concentrations have reported mean IQs that are closer to our revised IQ norms. ${ }^{26} 28$

We believe that the therapeutic 'window of safety' is narrow in young children with phenylketonuria who are treated early, and that mild, but important (and probably irreversible) neurological impairment commonly occurs as a result of the persisting disturbance of amino acid metabolism. In children with severe forms of the disorder it is difficult, if not impossible, to maintain phenylalanine concentrations consistently within the therapeutic range and this could well be an important factor in causing neurological damage. Fasting hypotyrosinaemia is also a regular finding in such children. In those with some residual enzyme activity smooth phenylalanine control can be achieved more readily (and fasting hypotryosinaemia is less common), and such children are likely to be over represented among subjects achieving the 'best treatment'.

What recommendations can be made concerning the management of phenylketonuria? First screening, which in the United Kingdom is based on a policy of testing between the sixth and 14th day after birth. ${ }^{14} 16$ This comparatively late timing (compared with other national programmes) has the advantage of increasing the difference in phenylalanine concentrations between infants with phenylketonuria and normal infants. Currently the average age at the start of treatment is 14-15 days, which is within the 'ideal' range of less than 21 days. Nevertheless, the importance of swift and efficient procedures for getting blood to the laboratory, analyses done, and children with positive tests diagnosed and treated, needs re-emphasis.

Finally, treatment policy; currently in most clinics the aim in early childhood is to control non-fasting blood phenylalanine concentrations at between $180-480 \mu \mathrm{mol} / \mathrm{l}$. Our findings suggest that this policy may need to be revised to one of controlling phenylalanine concentrations between $120-300 \mu \mathrm{mol} / \mathrm{l}$. Such a policy, however, runs the risk of causing more frequent hypophenylalaninaemia, which our study suggests is harmful. Attempts at stricter control would certainly require more frequent (twice a week) measurements of blood phenylalanine concentrations, and use of more precise methods of analysis than are often used. In considering the use of a more rigourous dietary regimen the possible risks, scientific uncertainties, cost, and sociological consequences for the children and their families will have to be taken into account.

The Medical Research Council (MRC) Steering Committee thank the parents and children for participating in the study, and the paediatricians, screening laboratory staff, and clinical and educational psychologists for supplying data to the register. The register is financed jointly by the Medical Research Council and Department of Health and is supervised by an MRC Steering Committee: Professor F Cockburn (chairman), Dr D Carson, Professor BE Clayton, Professor PJ Graham, Dr M Hally, Mr RD Jennings, Dr I Lister-Cheese, Mrs $M$ Lobascher, Professor RF Mahler, Dr I Smith, Dr I Sutherland, Professor AC
Turnbull, and Professor OH Wolff.

1 Hudson FP, Mordaunt VL, Leahy I. Evaluation of treatment begun in the first three months of life in 184 cases of phenylketonuria Arch Dis Child 1970;45:5-12.

2 Dobson JC, Williamson ML, Azen C, Koch R. Intellectual assessment of 111 four year old children with phenylketoassessment of 111 four year old chil
nuria. Pediatrics 1977;60:822-7.

3 Dobson JC, Kushida E, Williamson ML, Freidman EG. Intellectual performance of 36 phenylketonuric patients and their nonaffected siblings. Pediatrics 1976;58:53-8. 
comparisons between early treated phenylketonuria children and their matched sibling controls on intellectual and school achievement test results at eight years of age. $\mathcal{F}$ school achievement test results at
Inherited Metab Dis 1984;7:86-90.

5 Saudubray JM, Rey F, Ogier H, et al. Intelligence and school performance in early treated classical phenylketonuria patients. The French Collaborative Study. Eur $\mathcal{J}$ Pediatr patients. The French Colla

6 Smith I, Beasley M, Wolff OH, Ades EA. Behaviour disturbance in eight year old children with early treated phenylketonuria (PKU). f $\mathcal{F}$ Pediatr 1988;112:403-8.

$7 \mathrm{Smith} I$, Beasley $M$. Intelligence and behaviour in children with early treated phenylketonuria. Eur f Clin Nutr 1989; 43(suppl): $1-5$.

8 Smith I. The hyperphenylalaninaemias. In: Lloyd JK, Scriver CR, eds. Genetic and metabolic disease. Butterworth's International Medical Reviews. Pediatrics 5. London: Butterworth, 1985:166-209.

9 Hudson FP, Hawcroft J. The phenylketonuria register for the United Kingdom. In: Raine NR ed Medico-social management of inherited metabolic disease. London: Churchill Livingstone, 1977:217-24.

10 Flynn JR. The mean IQ of Americans: massive gains 19321978. Psychol Bull 1984;95:29-51.

11 Flynn JR. Massive IQ gains in 14 nations: what IQ tests really measure. Psychol Bull 1987;101:171-91.

12 Lynn R, Hampson SL, Mullineux JC. A longterm increase in the fluid intelligence of English children. Nature 1987;328: 797.

13 Hanson R, Aldridge Smith J. Achievements of young children on items of the Griffiths scales: 1980 compared with 1960. Child Care Health Dev 1987;13:181-95.

14 MRC/DHSS phenylketonuria register. Routine neonatal screening for phenylketonuria in the United Kingdom 1964-78. Br Med f 1981;282:1680-4.

15 Rutter M, Tizard J, Whitmore $\mathrm{K}$. Education, health and behaviour. London: Longman, 1970.

16 Grant DB, Smith I. Survey of neonatal screening for primary hypothyroidism in England, Wales and Northern Ireland 1982-84. Br Med F 1988:296:1355-8.

17 Wolff $\mathrm{OH}$, Smith I, Beasley M. Quelques limits de la classification et de la nomenclature des hyperphenylalaninemie. Arch Fr Pediatr 1987;44:635-8.

18 Registrar General Classification of occupations. London: HMSO, 1971 .

19 Office of Population and Census Surveys. Occupational mortality, England and Wales 1970-72. Series DS No 1. London: HMSO, 1978.

20 Brunner RL, Jordan MK, Berry HK. Early treated phenylketonuria: neuropsychologic consequences. $\mathcal{F}$ Pediatr 1983;102:831-5.

21 Pennington BF, van Doorninck WJ, McCabe LL, McCabe ERB. Neuropsychological deficits in early treated phenylketonuric children. Am $\mathcal{f}$ Ment Defic 1985;89:467-74.

22 Medical Research Council. Conference on phenylketonuria. Br Med F 1963;i:1961-3.

23 Francis DEM, Dixon DJW. Diets for sick children. 2nd ed. Oxford: Blackwell, 1970.

24 Naughton ER, Kiely B, Saul I, Murphy D. Phenylketonuria: outcome and problems in a diet for life clinic. Eur f Pediatr 1987;146(suppl 1):A23-4.

25 Williamson ML, Koch R, Azen C, Chang C. Correlates of intelligence and test results in treated phenylketonuric chilintelligence and test results in tre

26 Schmidt H, Mahle H, Michel U, Pietz J. Continuation versus discontinuation of low phenylalanine diet in PKU adolesdiscontinuation of low phenylalanine diet in PK

27 Hanley WB, Linsao L, Davidson W, Moes CAF. Malnutrition with early treatment of phenylketonuria. Pediatr Res 1970;4:318-27.

28 Williamson M, Dobson JC, Koch R. Collaborative study of children treated for phenylketonuria: study design. Pediatrics 1977;60:815-21.

29 Guttler F. Phenylketonuria: 50 years since Folling's discovery and still expanding our clinical and biochemical knowledge. Acta Paediatr Scand 1984;73:705-6. 